\title{
Leclercia adecarboxylata Causing Spontaneous Bacterial Peritonitis in a Child with Nephrotic Syndrome: A Case Report and Review of Literature
}

\author{
${ }^{1}$ Division of Pediatric Nephrology, Department of Pediatrics, \\ Advanced Pediatrics Centre, Post Graduate Institute of Medical \\ Education and Research, Sector 12, Chandigarh, India \\ 2Department of Microbiology, Research Block-A, Post Graduate \\ Institute of Medical Education and Research, Chandigarh, India. \\ J Lab Physicians:2020;12:222-224
}

ljas Hassan ${ }^{1}$ Parakriti Gupta ${ }^{2}$ Pallab Ray ${ }^{2} \quad$ Karalanglin Tiewsoh ${ }^{1, \odot}$

\begin{abstract}
Address for correspondence Karalanglin Tiewsoh, MD, 4th Floor A-Block, Division of Pediatric Nephrology, Department of Pediatrics, Advanced Pediatrics Center, PGIMER, Chandigarh 160012, India (e-mail: ktiewsoh@rediffmail.com).
\end{abstract}

\begin{abstract}
Infection is an important complication of childhood nephrotic syndrome (NS) and spontaneous bacterial peritonitis (SBP) is a frequently encountered one. We present a 7-year-old boy with NS who had decreased urine output, generalized body swelling, and abdominal pain. Urine analysis showed proteinuria of $50 \mathrm{mg} / \mathrm{m}^{2} / \mathrm{d}$. Ascitic tap showed total leukocyte count of 100 cells $/ \mathrm{mm}^{3}$, sugar of $67 \mathrm{mg} / \mathrm{dL}$, and protein of $1.1 \mathrm{~g} / \mathrm{dL}$. Gram stain revealed gram-negative bacilli with pus cells and culture grown Leclercia adecarboxylata (LAD). LAD was identified using matrix-assisted laser desorption ionization-time of flight mass spectrometry (MALDI-TOF MS) with an identification score of 2.0. The organism showed good susceptibility to common antibiotics. The boy

Keywords

- Leclercia adecarboxylata

- nephrotic syndrome

- spontaneous bacterial peritonitis had no direct contact with livestock and the source of infection remains speculative. Devitalized skin because of massive edema seems to be the most plausible site of entry for the organism. Our patient was started on ceftriaxone and improved. LAD is a rare opportunistic pathogen, which belongs to Enterobacteriaceae and usually causes soft tissue infections. As far as we know, this is the first case where it has caused peritonitis in a child with NS. We also reviewed other pediatric cases.
\end{abstract}

\section{Introduction}

Nephrotic syndrome (NS) is a common childhood glomerular disease, with infections as an important cause of morbidity and mortality. Of all infections, spontaneous bacterial peritonitis (SBP) and pneumonia is common. Studies have shown that gram-negative microorganisms like Escherichia coli can cause SBP. ${ }^{1}$ As far as we know, there is no report of Leclercia adecarboxylata (LAD) causing SBP in NS children. We report a case of NS presenting with $L A D$ peritonitis and a review of other LAD infections in pediatric cases reported in literature.

\section{Case History}

A 7-year-old boy diagnosed with NS presented with decreased urine output, generalized body swelling of 4 days duration, and pain in abdomen for 1 day. He was off steroids for past 1 year. On examination, he had anasarca with heart rate of $110 / \mathrm{min}$ and blood pressure of $90 / 60 \mathrm{~mm} \mathrm{Hg}$ (50th-90th centile). Urine analysis showed nephrotic range proteinuria with no pus cells/RBCs or red blood cells, suggestive of a relapse. The child had normal complete blood count (hemoglobin: $15.3 \mathrm{~g} / \mathrm{dL}$, total leukocyte count: $13,400 / \mathrm{mm}^{3}$, neutrophil: $89 \%$, lymphocyte: $7 \%$, and monocyte: $4 \%$ ). Renal function test
DOI https://doi.org/ 10.1055/s-0040-1721162 ISSN 0974-2727. (c) 2020. The Indian Association of Laboratory Physicians.

This is an open access article published by Thieme under the terms of the Creative Commons Attribution-NonDerivative-NonCommercial-License, permitting copying and reproduction so long as the original work is given appropriate credit. Contents may not be used for commercial purposes, or adapted, remixed, transformed or built upon. (https://creativecommons.org/licenses/by-nc-nd/4.0/) Thieme Medical and Scientific Publishers Pvt. Ltd., A-12, 2nd Floor, Sector 2, Noida-201301 UP, India 
was normal with blood urea of $23 \mathrm{mg} / \mathrm{dL}$ and serum creatinine of $0.27 \mathrm{mg} / \mathrm{dL}$. Ultrasound abdomen showed moderate ascites with no septations or internal echoes. His ascitic fluid analysis showed total leukocyte count of 100 cells $/ \mathrm{mm}^{3}$, sugar of $67 \mathrm{mg} / \mathrm{dL}$, and protein of $1.1 \mathrm{~g} / \mathrm{dL}$. Gram stain was performed which showed gram-negative bacilli with pus cells. Culture was done on blood and MacConkey agar, which revealed growth of lactose-fermenting colonies, similar to those of E. coli. LAD was identified using matrix assisted laser desorption ionization-time of flight mass spectrometry (MALDI-TOF MS; Bruker Daltonics, Bremen, Germany) with an identification score of 2.0. As a routine identification method, it is the policy in our laboratory to perform MALDI-TOF MS in all our cultures. Antimicrobial susceptibility was performed using Kirby-Bauer method and the isolate was found to be susceptible to cefotaxime, imipenem, meropenem, piperacillin-tazobactam, gentamicin, and ciprofloxacin. The boy came from a small town with no direct contact of any farm animals. Blood culture taken at the same time was sterile. Child was started on parenteral ceftriaxone for total of 7 days. Child improved clinically after 48 hours of antibiotic administration and was discharged after complete course of antibiotics on oral steroids for the treatment of NS.

\section{Discussion}

Infective complications in NS children occur because of various reasons like altered serum levels of immunoglobulins, abnormality of the complement system, and altered T-cell subpopulation and function. ${ }^{2}$

LAD was first identified by Leclerc in 1962. It is a motile, facultative, anaerobic, gram-negative bacilliform bacteria which has been isolated from food, water, and other environmental sources and is regarded as part of normal flora of animals and humans. However, now it is recognized as a pathogenic organism. This is partly because of enhanced detection by new bacterial assays like Micronaut-E (Merlin-Diagnostika, Bornheim, Germany), API 20E (bioMérieux, Marcy l'Etoile, France), and MALDI-TOF MS, which can distinguish LAD from other Escherichia species. ${ }^{3,4}$ Our isolate was also identified using MALDI-TOF MS.

As far as pathogenicity of LAD, exact mechanism is still not known, although cytotoxic effect has been demonstrated in vitro on human epithelial cells type $2 .^{5}$ Since majority of infections caused by LAD are soft tissue infections post trauma, the route of entry of LAD is considered to be skin disruption or catheter-related. Massive edema causing devitalization of skin may be the explanation of LAD causing SBP in NS.

Anuradha had reported two cases of infection with LAD from India, one from vaginal discharge in a 31-year-old female and another from a gluteal abscess in a healthy 50 -year-old man. These isolates were pan-sensitive to tested antibiotics (cephalosporins, amikacin, fluoroquinolones, and carbapenems). The first patient was treated with moxifloxacin and second one with doxycycline for 10 days, respectively. ${ }^{6}$

Case reports of children infected with LAD worldwide have been enumerated in - Table 1. Hurley et al reported a pediatric case in a healthy 2 -year-old child who presented with post traumatic right thumb abscess. The isolate was pan sensitive, except for intermediate sensitivity for piperacillin/tazobactam and child improved with parenteral ampicillin-sulbactam. ${ }^{7}$ In another report, a 9-year-old immunocompetent child who had post-traumatic LAD foot abscess, improved after surgical drainage and levofloxacin usage for 14 days. ${ }^{8}$ However, case reports of fatalities have also been reported in pediatric population. One child with colonic neuropathy and pseudo-obstruction acquired LAD infection, culminating into LAD sepsis. ${ }^{9}$ Another case who expired was a preterm, very low birth weight baby who had LAD sepsis and succumbed on day 54 of life in spite of receiving sensitive antibiotics for 21 days. ${ }^{10}$

No case of LAD causing SBP in NS has been reported so far, although one case of peritonitis has been reported from the West in a 5-year-old boy, who was on chronic peritoneal dialysis for end-stage renal disease. This child improved after receiving ceftazidime and intravenous plus intraperitoneal amikacin for a total of 10 days. ${ }^{14}$

Table 1 Summary of literature available on children infected with Leclerecia adecarboxylata

\begin{tabular}{|c|c|c|c|c|c|}
\hline Age & Underlying condition & $\begin{array}{l}\text { Type of } \\
\text { infection }\end{array}$ & Treatment received & Outcome & Reference \\
\hline $16 d$ & 26-wk infant in NICU & Sepsis & Cefotaxime $\times 14 \mathrm{~d}$ & Survived & Myers et $\mathrm{al}^{11}$ \\
\hline $31 d$ & 24-wk infant in NICU & Sepsis & Cefotaxime $\times 14 \mathrm{~d}$ & Died & Nelson et $a^{10}$ \\
\hline $8 \mathrm{mo}$ & $\begin{array}{l}\text { Gastroschisis/intestinal } \\
\text { atresia (TPN dependent) }\end{array}$ & Sepsis & ceftazidime + gentamicin $\times 21 \mathrm{~d}$ & Survived & Otani and Bruckner ${ }^{12}$ \\
\hline $11 \mathrm{mo}$ & $\begin{array}{l}\text { Acute lymphoblastic } \\
\text { leukemia }\end{array}$ & Sepsis & gentamicin + cefazolin “ $10 \mathrm{~d}$ & Survived & Longhurst and West. ${ }^{13}$ \\
\hline $5 y$ & End-stage renal disease & Peritonitis & $\begin{array}{l}\text { IV and peritoneal gentamicin } \\
\text { and ceftazidime } \times 10 \mathrm{~d}\end{array}$ & Survived & Fattal and Deville ${ }^{14}$ \\
\hline $5 y$ & $\begin{array}{l}\text { Colonic neuropathy, } \\
\text { Intestinal } \\
\text { pseudo-obstruction }\end{array}$ & Sepsis & $\begin{array}{l}\text { Ceftriaxone and amoxicillin/ } \\
\text { clavulanic acid } \times \text { total } 3 \mathrm{wk}\end{array}$ & Died & Sethi et al ${ }^{9}$ \\
\hline
\end{tabular}

Abbreviations: IV, intravenous; NICU, neonatal intensive care unit; TPN, total parenteral nutrition. 


\section{Conclusion}

We present a case report of peritonitis in a nephrotic child where the organism isolated was facultative anaerobic gram-negative bacilliform bacteria LAD using MALDI-TOF MS. Our isolate was sensitive to all the first line antibiotics and ceftriaxone was efficient in clearing the infection.

\section{Ethical Clearance}

An ethical clearance from Departmental Board was taken (DRB-121-19).

\section{Funding}

None.

\section{Conflict of Interest}

None.

\section{References}

1 Ajayan P, Krishnamurthy S, Biswal N, Mandal J. Clinical spectrum and predictive risk factors of major infections in hospitalized children with nephrotic syndrome. Indian Pediatr 2013;50(8):779-781

2 Wang CS, Greenbaum LA. Nephrotic syndrome. Pediatr Clin North Am 2019;66(1):73-85

3 Leclerc $\mathrm{H}$. Biochemical study of pigmented Enterobacteriaceae [in French]. Ann Inst Pasteur (Paris) 1962;102:726-741

4 Stock I, Burak S, Wiedemann B. Natural antimicrobial susceptibility patterns and biochemical profiles of Leclercia adecarboxylata strains. Clin Microbiol Infect 2004;10(8):724-733
5 Muresu R, Maddau G, Delogu G, Cappuccinelli P, Squartini A. Bacteria colonizing root nodules of wild legumes exhibit virulence-associated properties of mammalian pathogens. Antonie van Leeuwenhoek 2010;97(2):143-153

6 Anuradha M. Leclercia adecarboxylata isolation: case reports and review. J Clin Diagn Res 2014;8(12):DD03-DD04

7 Hurley EH, Cohen E, Katarincic JA, Ohnmacht RK. Leclercia adecarboxylata infection in an immunocompetent child. R I Med J (2013) 2015;98(9):41-44

8 Grantham WJ, Funk SS, Schoenecker JG. Leclercia adecarboxylatamusculoskeletal infection in an immune competent pediatric patient: an emerging pathogen? Case Rep Orthop 2015;2015:160473

9 Sethi K, Barker EM, Metlay LA, Caserta MT, Daugherty LE. Leclercia adecarboxylata sepsis and cerebral herniation. J Pediatric Infect Dis Soc 2014;3(1):e1-e3

10 Nelson MU, Maksimova Y, Schulz V, Bizzarro MJ, Gallagher PG. Late-onset Leclercia adecarboxylata sepsis in a premature neonate. J Perinatol 2013;33(9):740-742

11 Myers KA, Jeffery RM, Lodha A. Late-onset Leclercia adecarboxylata bacteraemia in a premature infant in the NICU. Acta Paediatr 2012;101(1):e37-e39

12 Otani E, Bruckner DA. Leclercia adecarboxylata isolated from a blood culture. Clin Microbiol Newsl 2015;13(20):157-158

13 Longhurst CA, West DC. Isolation of Leclercia adecarboxylata from an infant with acute lymphoblastic leukemia. Clin Infect Dis 2001;32(11):1659

14 Fattal O, Deville JG. Leclercia adecarboxylata peritonitis in a child receiving chronic peritoneal dialysis. Pediatr Nephrol 2000;15(3-4):186-187 